\title{
Poziomy metali szkodliwych dla zdrowia w różnych typach żywności
}

\author{
Levels of Metals Harmful to Health in Various Types of Food
}

\author{
Katarzyna Góralczyk ${ }^{1}$, Anita Dziubak ${ }^{2}$, Adrianna Kręźlewicz² \\ ${ }^{1}$ Instytut Nauk Biologicznych, Uniwersytet Kardynała Stefana Wyszyńskiego w Warszawie \\ ${ }^{2}$ Centrum Ekologii i Ekofilozofii, Uniwersytet Kardynała Stefana Wyszyńskiego w Warszawie \\ ORCID: KG https://orcid.org/0000-0002-9839-2449•k.goralczyk@uksw.edu.pl \\ Zgłoszono: 17.11.2020; zrecenzowano: 8.01.2021; zaakceptowano do druku: 14.01.2021
}

\begin{abstract}
Streszczenie: Zdrowie człowieka w dużym stopniu zależy od jego przyzwyczajeń żywieniowych. Dlatego tak istotne jest, aby spożywać żywność o odpowiedniej jakości zarówno pod względem odpowiedniej zawartości w niej składników odżywczych, jak i dopuszczalnej obecności różnych zanieczyszczeń. Jeśli chodzi o te ostatnie, to w żywności powszechnie występują metale i ich związki, których zawartość w głównej mierze wynika z powszechnej ich obecności w różnych elementach środowiska. 0 jakości zdrowotnej żywności świadczą przede wszystkim poziomy mikro- i makroelementów. Materiał i metody: Materiał do badań stanowiły próbki żywności z produkcji ekologicznej i konwencjonalnej. Do badań wytypowano najpopularniejsze w diecie w naszym kraju owoce i warzywa, odpowiednio: jabłka i marchew. W próbkach tych oznaczano metodą spektrometrii emisyjnej ze wzbudzeniem plazmowym (ICP-OES) poziomy metali szkodliwych dla zdrowia: kadm (Cd), ołów (Pb), arsen (As) i rtęć (Hg), a także wybrane mikro- i makroelementy: wapń (Ca), potas (K), magnez (Mg), fosfor (P), żelazo (Fe), mangan (Mn), cynk (Zn) i glin (Al). Próbki były poddawane mineralizacji mikrofalowej. Wyniki: Zawartość metali szkodliwych dla zdrowia ( $\mathrm{Pb}, \mathrm{Cd}, \mathrm{Hg}, \mathrm{As}$ ) w badanych próbkach jabłek i marchwi były znacznie niżzze od najwyższych dopuszczalnych poziomów ustalonych w ustawodawstwie unijnym i nie różniły się istotnie w uprawach konwencjonalnych vs. ekologicznych. Podobne rezultaty wykazano w przypadku mikro- i makroelementów.
\end{abstract}

Słowa kluczowe: metale szkodliwe dla zdrowia, mikro- i makroelementy, żywność konwencjonalna, żywność ekologiczna, bezpieczeństwo żywności

\begin{abstract}
Top-level human health depends on people's eating habits. That is why, it is important to consume good quality food, both in terms of the presence of various contaminants, and the content of nutrients. Food contaminants, metals, and their compounds, are commonly found, since their presence in food, results from their common presence in various elements of the environment. The levels of micro-elements and macro-nutrients also testify to the health quality of food. Materials and methods: The materials for the study were food samples from organic and conventional production. The most popular fruit and vegetables in the diet in Poland, i.e., apples and carrots, were selected for research. The method of plasma excitation spectrometry (ICP-OES) was used to study the levels of metals harmful to health: cadmium (Cd), lead $(\mathrm{Pb})$, arsenic $(\mathrm{As})$, and mercury $(\mathrm{Hg})$, as well as selected micro-elements and macro-nutrients: calcium (Ca), potassium (K), magnesium (Mg), phosphorus (P), iron (Fe), manganese (Mn), zinc ( $\mathrm{Zn})$, and aluminium (Al), in selected food products. Samples were mineralised by microwave techniques. Results: The content of harmful metals ( $\mathrm{Pb}, \mathrm{Cd}, \mathrm{Hg}, \mathrm{As})$ in the tested apple and carrot samples were significantly lower than the maximum levels set in EU legislation, and did not differ, significantly, in conventional food vs. ecological. Similar results were also shown for micro-elements and macro-nutrients.
\end{abstract}

Keywords: metals harmful to health, micro-elements and macro-nutrients, conventional food, organic food, food safety 


\section{Wstęp}

Zdrowie człowieka w dużym stopniu zależy od przyzwyczajeń żywieniowych. Dlatego tak istotne jest spożywanie żywności o odpowiedniej jakości zdrowotnej. Dotyczy to zarówno odpowiedniej zawartości w niej składników odżywczych, jak i obecności różnych zanieczyszczeń. Wśród tych ostatnich powszechnie występującą grupą są metale i ich związki, których obecność w żywności w głównej mierze wynika z ich stałej obecności w różnych elementach środowiska (Gawęcki 2011, 40-41, 53-55; Gawęcki 2012, 560).

Pierwiastki śladowe i ich związki są naturalnymi i nieodłącznymi elementami środowiska przyrodniczego. Niestety działalność człowieka powoduje uwalnianie nadmiernych ilości metali do środowiska, co w pewnym stopniu powoduje również ich włączenie w łańcuch żywieniowy. Do niezbędnych pierwiastków mających ogromne znaczenie dla prawidłowego funkcjonowania organizmu należą makroelementy, takie jak: magnez (Mg), wapń (Ca) czy potas (K), oraz mikroelementy: żelazo (Fe), miedź $(\mathrm{Cu})$, cynk (Zn), kobalt (Co), nikiel $(\mathrm{Ni})$, selen (Se), wanad (V), chrom (Cr), mangan (Mn) oraz molibden (Mo). Mikro- i makroelementy wpływają pozytywnie na organizm człowieka tylko wtedy, gdy dostarczane są w optymalnych stężeniach. Każda sytuacja odbiegająca od optymalnej zawsze wpływa niekorzystnie na prawidłowe funkcjonowanie organizmu. Dotyczy to zarówno za niskich, jak i za wysokich poziomów pierwiastków śladowych. Natomiast niezależnie od stężeń występowanie w środowisku, a w konsekwencji w żywności, pierwiastków szkodliwych dla zdrowia człowieka, takich jak kadm (Cd), rtęć (Hg), arsen (As) i ołów $(\mathrm{Pb})$, zawsze niekorzystnie wpływa na zdrowie ludzi i zwierząt. Pierwiastki te i ich sole mogą być przyczyną przewlekłych i niebezpiecznych zatruć, które mogą trwale wpłynąć na funkcje organizmu. Na poziomy tych metali w organizmie człowieka znaczący wpływ mają: sposób odżywiania, przyjęta dawka, szybkość usuwania, a także drogi wchłaniania (EFSA 2004, 1-20; DGKS 2014, 16; Iwanow et al. 2012, 220; Kieliszek 2019, 1298; Nazarewicz 2007, 23-27).

Ołów należy do grupy szczególnie toksycznych metali, który może oddziaływać niekorzystnie na pracę układu sercowo-naczyniowego, moczowego, nerwowego i immunologicznego. Wpływa również znacząco na potencję oraz może powodować mutacje genetyczne prowadzące w konsekwencji do procesów nowotworowych. Ołów pośrednio może być przyczyną podwyższonego ciśnienia tętniczego i może spowodować zaburzenie funkcji nerek. Z kolei kadm uważany jest za najbardziej toksyczny z metali. Głównym jego źródłem dla organizmu człowieka jest żywność, $75 \%$ kadmu w codziennej diecie pochodzi z produktów pochodzenia roślinnego. Największe destrukcje sieje on w narządach, w których dosyć łatwo się kumuluje, tj. w nerkach, wątrobie, jądrach i kościach, a także może wpływać na osłabienie pracy układu odpornościowego. Niezwykle toksyczne działanie wykazuje również rtęć, a jej oddziaływanie na organizm człowieka w dużej mierze zależy od formy, w jakiej występuje, od sposobu wniknięcia do organizmu, dawki i czasu ekspozycji. Najbardziej groźne dla człowieka są jej organiczne związki, np. metylortęć, ponieważ może uszkadzać ośrodkowy układ nerwowy. Ponadto rtęć powoduje zaburzenia pracy układu immunologicznego i nerwowego. Natomiast arsen występuje powszechnie w środowisku, m.in. w wodzie deszczowej czy morskiej i wodach gruntowych. Komisja Kodeksu Żywnościowego FAO/WHO określiła, że dzienna dawka dla dorosłego człowieka nie może przekraczać o,05 $\mathrm{mg} / \mathrm{kg}$ m.c. Według badań prowadzonych w różnych ośrodkach naukowych substancje zawierające arsen przyczyniają się do powstawania nowotworów, głównie wątroby, płuc i skóry (Wojciechowska-Mazurek et al. 1996, 423431; 2006, 546-549; 2008, 251-266; 2010a, 27-35; 2010b, 45-48; 2010c, 233-239; 2011, 143-149; Mania et al. 2011, 96-100; Duma et al. 2012, 94-100; Ociepa-Kubicka i Ociepa 
2012, 169-180; Staniak 2014, 36-45; Gajewska et al. 2016, 43-51; Szymonik 2016, 48-53).

Celem pracy było zbadanie i porównanie poziomów metali szkodliwych dla zdrowia w próbkach żywności z produkcji konwencjonalnej i ekologicznej na tle prawnie dopuszczalnych poziomów, a także porównanie różnic w poziomach pierwiastków śladowych w środkach spożywczych z obu produkcji.

\section{Materiał i metody}

Materiał do badań stanowiły próbki żywności z produkcji ekologicznej i konwencjonalnej. Do badań wytypowano najpopularniejsze w diecie w naszym kraju owoce i warzywa. Spośród owoców wybrano jabłka ze względu na ich duży udział w diecie różnych grup wiekowych oraz marchew jako przedstawiciela warzyw powszechnie stosowanych w żywności zarówno w populacji generalnej, jak i w przypadku diet wykluczeniowych. Próbki żywności konwencjonalnej kupowano w supermarketach, a żywność ekologiczną w sklepach z żywnością organiczną w lokalizacji pobliskiej do ww. supermarketów.

Oznaczanie zawartości metali szkodliwych dla zdrowia i innych, wybranych pierwiastków przeprowadzono metodą spektrometrii emisyjnej ze wzbudzeniem plazmowym (ICP-OES). Technika ta umożliwia równoczesne oznaczanie ponad 70 pierwiastków, dodatkowo cechuje ją wysoka precyzja. Do procesu atomizacji i wzbudzenia wykorzystywane są fale radiowe o wysokiej częstotliwości, umożliwiające wytworzenie plazmy o wysokiej temperaturze (ok. 7000 K). Dzięki niej związki chemiczne rozpadają się do atomów, a następnie ulegają wzbudzeniu, po czym emitują pochłoniętą energię w postaci promieniowania elektromagnetycznego charakterystycznego dla danego pierwiastka. Spektrometr emisyjny ICP-OES pracował w następujących warunkach: częstotliwość generatora - 27,12 MHz, moc generatora $-1,20 \mathrm{~kW}$, całkowity przepływ gazu (argonu) - 10,0o l/min, przepływ gazu nośnego (argonu) - o,7o l/min, przepływ gazu pomocniczego (argonu) - o,6o l/min, czas ekspozycji - 30 s, liczba ekspozycji na próbę - 3, czas przemywania układu - 30 s, obroty pompy perystaltycznej - 20-60 obr./min.

Badaną próbkę - po odważeniu nie więcej niż o,5 g i umieszczeniu w teflonowym naczyniu wraz z stężonym kwasem azotowym, stężonym kwasem solnym oraz nadtlenkiem wodoru - poddawano mineralizacji mikrofalowej przez ok. 35 min. Tak przygotowany roztwór przenoszono do kolby miarowej, uzupełniano wodą dejonizowaną i poddawano oznaczeniu ICP-OES w podanych powyżej warunkach. W ramach kontroli jakości wyników równolegle z próbkami badanymi oznaczano próbki odczynnikowe, aby wyeliminować wpływ odczynników stosowanych w badaniu na wynik końcowy badania.

Uzyskane wyniki poddawano analizie statystycznej, stosując powszechnie dostępne programy obliczeniowe.

\section{Wyniki i dyskusja}

W ramach nadzoru nad bezpieczeństwem żywności znajdującej się w obrocie handlowym we wszystkich Państwach Członkowskich Unii Europejskiej prowadzony jest ujednolicony monitoring żywności na zgodność z prawem żywnościowym według wytycznych zawartych w Rozporządzeniu Parlamentu Europejskiego i Rady Nr 882/2004. Zasady prowadzenia skoordynowanego monitoringu żywności narzucają Państwom Członkowskim konieczność prowadzenia systematycznych badań laboratoryjnych żywności pod kątem obecności różnych zanieczyszczeń, w tym również metali szkodliwych dla zdrowia. Badania te z ramienia Komisji Europejskiej nadzoruje i koordynuje Europejski Urząd ds. Bezpieczeństwa Żywności (EFSA - European Food Safety Agency), który następnie przygotowuje roczne, zbiorcze raporty zawierające statystyczną ocenę jakości żywności.

W Polsce badania urzędowej kontroli żywności koordynuje Państwowa Inspekcja Sanitarna (PIS), a wykonywane są w laboratoriach Wojewódzkich Stacji 
Sanitarno-Epidemiologicznych (WSSE). W tabeli 1 przedstawiono średnie stężenia metali szkodliwych dla zdrowia w wybranych produktach spożywczych otrzymanych na podstawie wieloletniego, skoordynowanego planu monitoringu żywności w Polsce (Wojciechowska-Mazurek et al. 1996, 423431; 2006, 546-549; 2008, 251-266; 2010a, 27-35; 201ob, 45-48; 2010c, 233-239; 2011, 143-149).

Posługując się zasadami opisanymi w rozporządzeniu nr 882/2004, w niniejszej pracy podjęto próbę oceny wybranych produktów spożywczych pod kątem zawartości różnych pierwiastków, ze szczególnym uwzględnieniem metali szkodliwych dla zdrowia. W badaniach oznaczano poziomy metali szkodliwych dla zdrowia (kadm, ołów, rtęć i arsen) w próbkach jabłek i marchwi z produkcji konwencjonalnej i ekologicznej. W przebadanych próbkach nie wykryto obecności rtęci i arsenu, dlatego tabela 2 przedstawia tylko oznaczone stężenia ołowiu i kadmu w badanych próbkach.

W przebadanych próbkach jabłek i marchwi zarówno z produkcji konwencjonalnej, jak i ekologicznej wykryte poziomy dla wybranych związków są zbliżone do tych uzyskiwanych w ramach urzędowej kontroli, a zaobserwowane różnice nie są znaczące statystycznie (Wojciechowska-Mazurek et al. 1996, 423-431; 2006, 546-549; 2008, 251266; 2010a, 27-35; 2010b, 45-48; 2010c, 233239; 2011, 143-149). Jednocześnie są nieco niższe, zwłaszcza w przypadku żywności z produkcji ekologicznej, jeśli porównamy je do wyników uzyskiwanych przez innych autorów (Gajewska et al. 2016, 43-51; Staniak 2014, 36-45; Szymonik 2016, 48-53). Wykrywane poziomy metali szkodliwych dla zdrowia w obu typach żywności są bezpieczne dla człowieka, ponieważ stężenia te są poniżej najwyższych dopuszczalnych poziomów (NDP) tych pierwiastków w żywności (Rozporządzenie 2006), a także ich spożycie jest niższe od wartości PTWI (Provisional Tolerable Weekly Intake, czyli tymczasowe tolerowane tygodniowe pobranie) (EFSA 2009, 139). Wartości NDP i PTWI dla czterech badanych metali szkodliwych dla zdrowia przedstawiono $\mathrm{w}$ tabeli 3 .

W produkcji roślinnej zarówno konwencjonalnej, jak i ekologicznej oprócz pierwiastków szkodliwych dla zdrowia występują

Tabela 1. Średnie stężenia metali szkodliwych dla zdrowia w próbkach żywności w Polsce

\begin{tabular}{lcccc}
\hline \multicolumn{1}{c}{ Produkt spożywczy } & $\begin{array}{c}\text { Kadm } \\
{[\mathrm{mg} / \mathrm{kg}]}\end{array}$ & $\begin{array}{c}\text { Ołów } \\
{[\mathrm{mg} / \mathrm{kg}]}\end{array}$ & $\begin{array}{c}\text { Arsen } \\
{[\mathrm{mg} / \mathrm{kg}]}\end{array}$ & $\begin{array}{c}\text { Rtę́́ } \\
{[\mathrm{mg} / \mathrm{kg}]}\end{array}$ \\
\hline $\begin{array}{l}\text { Wody mineralne i napoje } \\
\text { bezalkoholowe }\end{array}$ & 0,002 & 0,009 & 0,008 & 0,001 \\
\hline Owoce świeże i przetwory & 0,003 & 0,026 & 0,017 & 0,002 \\
\hline Warzywa i przetwory & 0,011 & 0,042 & 0,025 & 0,003 \\
\hline Zboża & 0,024 & 0,041 & 0,014 & 0,003 \\
\hline Suplementy diety & $\mathrm{n} . \mathrm{b}$. & 0,087 & $\mathrm{n} . \mathrm{b}$. & 0,003 \\
\hline Produkty dla dzieci & 0,005 & 0,016 & 0,032 & 0,002 \\
\hline
\end{tabular}

n.b. - nie badano

Tabela 2. Średnie stężenia ołowiu i kadmu w jabłkach i marchwi z produkcji konwencjonalnej i ekologicznej

\begin{tabular}{lcc}
\hline \multicolumn{1}{c}{ Pierwiastek } & $\begin{array}{c}\text { Ołów } \\
{[\mathrm{mg} / \mathrm{kg}]}\end{array}$ & $\begin{array}{c}\mathrm{Kadm} \\
{[\mathrm{mg} / \mathrm{kg}]}\end{array}$ \\
\hline Jabłka z produkcji konwencjonalnej & 0,025 & 0,01 \\
\hline Jabłka z produkcji ekologicznej & n.w. & n.w. \\
\hline Marchew z produkcji konwencjonalnej & n.w. & 0,09 \\
\hline Marchew z produkcji ekologicznej & n.w. & n.w. \\
\hline
\end{tabular}


Tabela 3. Najwyższe dopuszczalne stężenia i wartości PTWI dla kadmu, ołowiu, arsenu i rtęci

\begin{tabular}{|c|c|c|}
\hline Pierwiastek & $\begin{array}{c}\text { NDP } \\
{[\mathrm{mg} / \mathrm{kg} \text { produktu] }}\end{array}$ & $\begin{array}{c}\text { PTWI } \\
\text { [mg/kg m.c.] }\end{array}$ \\
\hline $\operatorname{Kadm}(\mathrm{Cd})$ & 0,1 & 0,007 \\
\hline Ołów (Pb) & 0,1 & 0,025 \\
\hline Arsen (As) & 0,5 & 0,015 \\
\hline Rtęć(Hg) & 0,01 & $\begin{array}{l}0,005 \\
0,0016 \mathrm{Hg} \text { org }\end{array}$ \\
\hline
\end{tabular}

m.c. - masa ciała

również pierwiastki, które wliczane są do tzw. wartości odżywczych żywności. Dlatego wykorzystując technikę ICP-OES w tych samych próbkach i w tych samych seriach pomiarowych, można też zidentyfikować inne pierwiastki. Wykorzystując te możliwości w omawianych badaniach, zidentyfikowano również inne obecne w próbkach pierwiastki i porównano ich poziomy w obu typach żywności. Były to m.in. wapń $(\mathrm{Ca})$, potas $(\mathrm{K})$, magnez (Mg), fosfor (P), żelazo (Fe), mangan (Mn), cynk (Zn) i glin (Al). Oznaczenie tych pierwiastków umożliwiło włączenie się do odwiecznej dyskusji czy żywność ekologiczna ma większe walory odżywcze od żywności konwencjonalnej. Podobnie jak to stwierdzali inni autorzy, w niniejszych badaniach zaobserwowano pewne różnice w poziomach poszczególnych pierwiastków, ale różnice te są nieistotne statystycznie (Łozińska-Wróbel and Pachnowska 2017; Śmiechowska i Florek 2011, 152-156). Porównanie poziomów mikro- i makroelementów: wapnia $(\mathrm{Ca})$, potasu $(\mathrm{K})$, magnezu $(\mathrm{Mg})$, fosforu (P), żelaza (Fe), manganu (Mn), cynku ( $\mathrm{Zn})$ i glinu (Al) w badanych próbkach żywności konwencjonalnej i ekologicznej oraz kadmu (Cd), przedstawiciela metali szkodliwych dla zdrowia w obu typach żywności, zilustrowano na wykresach 1 i 2.

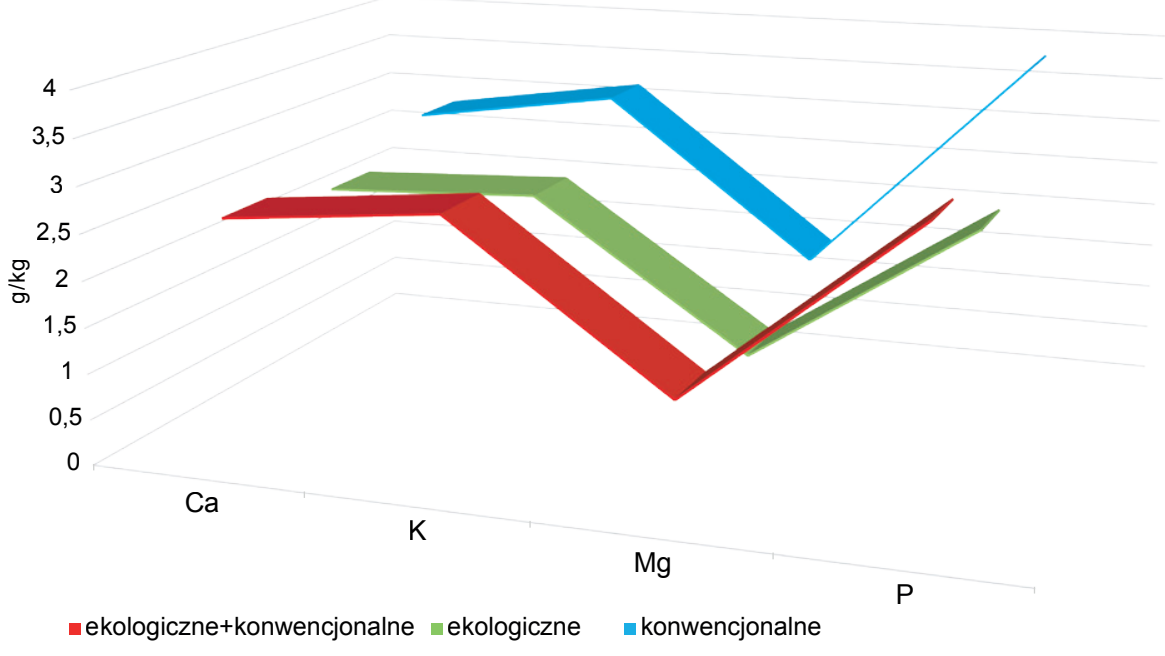

Wykres 1. Średnie stężenia wybranych pierwiastków (wapnia, potasu, magnezu i fosforu) w uprawach konwencjonalnych i ekologicznych 


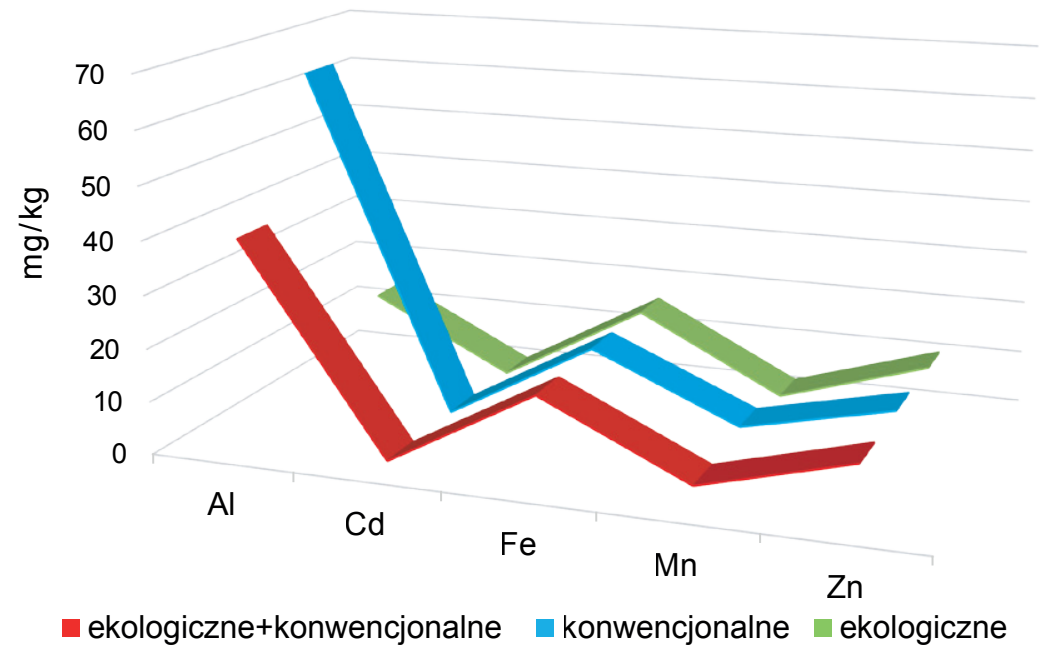

Wykres 2. Średnie stężenia wybranych pierwiastków (glinu, kadmu, żelaza, manganu, cynku) w uprawach konwencjonalnych i ekologicznych

\section{Podsumowanie}

Zawartość metali szkodliwych dla zdrowia $(\mathrm{Pb}, \mathrm{Cd}, \mathrm{Hg}, \mathrm{As})$ w badanych środkach spożywczych, tj. jabłkach i marchwi, które stanowią istotny element diety dla różnych grup wiekowych w Polsce, była znacznie niższa od najwyższych dopuszczalnych poziomów ustalonych w ustawodawstwie unijnym. Nie ma też istotnych różnic w zanieczyszczeniu produktów z upraw konwencjonalnych i ekologicznych. Podobne rezultaty otrzymywane są w ramach urzędowej kontroli żywności zarówno w Polsce, jak i innych państwach członkowskich Unii Europejskiej. Na potwierdzenie tego faktu można przytoczyć roczny raport przygotowany w ramach działalności Systemu Wczesnego Ostrzegania o Niebezpiecznej Żywności i Paszach (RASFF - Rapid Alert System for Food and Feed), w którym w 2018 r. wykazano tylko 24 przypadki powiadomień dotyczących niebezpiecznych dla zdrowia poziomów metali w środkach spożywczych oraz w wyniku migracji z materiałów i wyrobów przeznaczonych do kontaktu z żywnością, a także obecności ciał obcych (RASFF 2019). W badaniach tych wykazano, że kadm jest drugim po rtęci pierwiastkiem pod względem ilości tych powiadomień. Należy podkreślić, że dotyczą one głównie przekroczeń tych zanieczyszczeń w owocach morza.

Jednocześnie w naszych badaniach nie wykazano również istotnych różnic w poziomach wybranych mikro- i makroelementów, które mogą odpowiadać za wartość odżywczą żywności w obu typach produkcji roślinnej.

\section{Stosowane skróty}

$\mathrm{Al}$ - glin

As - arsen

Ca - wapń

$\mathrm{Cd}-\mathrm{kadm}$

Co - kobalt

$\mathrm{Cr}-$ chrom

$\mathrm{Cu}-$ miedź

EFSA - Europejski Urząd ds. Bezpieczeństwa

Żywności (European Food Safety Agency)

FAO/WHO - Organizacja Narodów

Zjednoczonych do spraw Wyżywienia

i Rolnictwa (Food and Agriculture

Organization of the United Nations/World

Health Organization)

$\mathrm{Fe}$ - żelazo

$\mathrm{Hg}$ - rtęć 
ICP-OES - emisyjna spektrometria atomowa $\mathrm{w}$ plazmie (inductively coupled plasma atomic emission spectroscopy)

$\mathrm{K}$ - potas

Mg - magnez

Mn - mangan

Mo - molibden

$\mathrm{Ni}-$ nikiel

NDP - najwyższy dopuszczalny poziom

$\mathrm{P}$ - fosfor

PIS - Państwowa Inspekcja Sanitarna

$\mathrm{Pb}$ - ołów

PTWI - tymczasowe tolerowane tygodniowe pobranie (Provisional Tolerable Weekly Intake)

RASFF - System Wczesnego Ostrzegania o Niebezpiecznej Żywności i Paszach (Rapid Alert System for Food and Feed)

$\mathrm{Se}$ - selen

$\mathrm{Zn}$ - cynk

$\mathrm{V}$ - wanad

WSSE - Wojewódzka Stacja

Sanitarno-Epidemiologiczna

\section{Bibliografia}

DGKS (Dyrekcja Generalna ds. Komunikacji Społecznej). 2014. Bezpieczeństwo żywności. «Od pola do stotu» - bezpieczna i zdrowa żywność dla każdego. Luxembourg: Publications Office. https:// doi.org/10.2775/78879.

Duma, Paulina, Małgorzata Pawlos, i Mariusz Rudy. 2012. „Zawartość metali ciężkich w wybranych produktach spożywczych województwa podkarpackiego." Bromatogia $i$ Chemia Toksykologiczna 45(1): 94-100.

EFSA. 2004. "Report of the scientific panel on contaminants in the food chain on provisional findings on furan in food." EFSA Journal 137: 1-20.

EFSA. 2009. "Scientific opinion of the Panel on Contaminants in the Food Chain on a request from the European Commission on cadmium in food." EFSA Journal 980: 1-139.

Gajewska, Magdalena, Anna Czajkowska-Mysłek, i Anna Głowacka, 2016. „Ocena zawartości kadmu i ołowiu w wybranych suszach roślin przyprawowych." Postępy Nauki i Technologii Przemystu Rolno-Spożywczego 71(1): 43-51.

Gawęcki, Jan. 2011. Żywienie człowieka a zdrowie publiczne. Warszawa: Wydawnictwo Naukowe PWN.
Gawęcki, Jan. 2012. Żywienie człowieka. Podstawy nauki o żywieniu. Warszawa: Wydawnictwo Naukowe PWN.

Iwanow, Krystyna, Hanna Kunachowicz, i Irena Nadolna. 2012. Wartość odżywcza wybranych produktów spożywczych i typowych potraw. Warszawa: PZWL.

Kieliszek, Marek. 2019. "Selenium - fascinating microelement, properties and sources in food." Molecules 24: 1298. https://doi.org/10.3390/ molecules24071298.

Łozińska-Wróbel, Katarzyna, and Beata Pachnowska. 2017. Organic food in Poland. Wrocław: IMAS International Sp. z o.o.

Mania, Monika, Maria Wojciechowska-Mazurek, Krystyna Starska, Małgorzata Rebeniak, i Urszula Biernat. 2011. „Nowe fakty o ołowiu w środkach spożywczych.” Przemyst Spożywczy 65: 96-100.

Nazarewicz, Rafał. 2007. „Wpływ stosowania diety wegetariańskiej na wybrane parametry morfologiczne i biochemiczne krwi." Roczniki Państwowego Zakładu Higieny 58(1): 23-27.

Ociepa-Kubicka, Agnieszka, i Ewa Ociepa. 2012. "Toksyczne oddziaływanie metali ciężkich na rośliny, zwierzęta i ludzi." Inżynieria i Ochrona Środowiska 15(2): 169-180.

RASFF. 2019. The Rapid Alert System for Food and Feed. 2018 Annual Report. Luxembourg: Publications Office of the European Union. https:// doi.org/10.2875/914558.

Rozporządzenie 2004 - Rozporządzenie (WE) Nr 882/2004 Parlamentu Europejskiego i Rady z dnia 29 kwietnia 2004 r. w sprawie kontroli urzędowych przeprowadzanych w celu sprawdzenia zgodności z prawem paszowym i żywnościowym oraz regułami dotyczącymi zdrowia zwierząt i dobrostanu zwierząt (Dz. Urz. UE z 30.04.2004 r. L 191/1 z późniejszymi zmianami).

Rozporządzenie 2006 - Rozporządzenie Komisji (WE) Nr 1881/2006 z 19.12.2006 r. ustalające najwyższe dopuszczalne poziomy niektórych zanieczyszczeń w środkach spożywczych (Dz. Urz. UE z 20.12.2006 r., L 364/5 z późniejszymi zmianami).

Staniak, Sylwia. 2014. „Źródła i poziom zawartości ołowiu w żywności." Polish Journal of Agronomy 19: $36-45$.

Szymonik, Anna. 2016. „Zawartość kadmu i ołowiu w warzywach, efekt toksyczności pierwiastków 
śladowych." Edukacja Biologiczna i Środowiskowa 3: 48-53.

Śmiechowska, Maria, i Agnieszka Florek. 2011. "Zawartość metali ciężkich w wybranych warzywach $\mathrm{z}$ uprawy konwencjonalnej, ekologicznej i działkowej." Journal of Research and Applications in Agricultural Engineering 56(4): 152-156.

Wojciechowska-Mazurek, Maria, Kazimierz Karłowski, Jan T. Kumpulainen, Krystyna Starska, Elżbieta Brulińska-Ostrowska, i Kazimiera ĆwiekLudwicka. 1996. „Lead, cadmium, mercury, copper and zinc in Polish powdered milk and products for infants and children. Natural antioxidants and food quality in atherosclerosis and cancer prevention." The Royal Society of Chemistry 181: 423-431.

Wojciechowska-Mazurek, Maria, Krystyna Starska, Elżbieta Brulińska-Ostrowska, Monika Plewa, Urszula Biernat, i Kazimierz Karłowski. 2006. "Assessment of contamination of cereal products with elements noxious to human health." Polish Journal of Environmental Studies 15: 546-549.

Wojciechowska-Mazurek, Maria, Krystyna Starska, Elżbieta Brulińska-Ostrowska, Monika Plewa, Urszula Biernat, i Kazimierz Karłowski. 2008. „Monitoring zanieczyszczenia żywności pierwiastkami szkodliwymi dla zdrowia. Część I. Produkty zbożowe, pszenne, warzywne, cukiernicze oraz produkty dla niemowląt i dzieci (rok 2004)." Roczniki Państwowego Zaktadu Higieny 59(3): 251-266.

Wojciechowska-Mazurek, Maria, Krystyna Starska, Elżbieta Brulińska-Ostrowska, Monika Plewa, Urszula Biernat, i Kazimierz Karłowski. 2010a. „Monitoring zanieczyszczenia żywności pierwiastkami szkodliwymi dla zdrowia. Część II. Wody mineralne, napoje bezalkoholowe, owoce, orzechy, ryż, soja, ryby i owoce morza." Roczniki Państwowego Zaktadu Higieny 61(1): 27-35.

Wojciechowska-Mazurek, Maria, Monika Mania, Krystyna Starska, i Małgorzata Opoka, 2010b. „Kadm w środkach spożywczych - celowość obniżenia limitów." Przemyst Spożywczy. Żywność - Żywienie - Bezpieczeństwo zdrowotne 64(2): $45-48$.

Wojciechowska-Mazurek, Maria, Krystyna Starska, Monika Mania, Małgorzata Rebeniak, i Kazimierz Karłowski. 2010c. „Pierwiastki szkodliwe dla zdrowia w herbacie - ocena zagrożenia dla zdrowia." Bromatologia i Chemia Toksykologiczna 43(3): 233-239.

Wojciechowska-Mazurek, Maria, Monika Mania, Krystyna Starska, Małgorzata Rebeniak, i Kazimierz Karłowski. 2011. „Pierwiastki szkodliwe dla zdrowia w grzybach jadalnych w Polsce." Bromatologia i Chemia Toksykologiczna 44(2): 143-149. 